\title{
Design And Development Of An External Glass Wall Cleaning System
}

\author{
Mahendra kumar $\mathrm{C}^{\mathrm{a}}$, Bapu Gowda $\mathrm{C} \mathrm{M}^{\mathrm{b}}$, Prema $\mathrm{S}^{\mathrm{c}}$
}

${ }^{a}$ Assistant Professor, Department of Mechanical Engineering, BNM Institute of Technology, Bengaluru, India

${ }^{\mathrm{b}}$ Assistant Professor, Department of Mechanical Engineering, BNM Institute of Technology, Bengaluru, India

${ }^{c}$ Assistant Professor, Department of Mechanical Engineering, RNS Institute of Technology, Bengaluru, India

\begin{abstract}
The increasing number of skyscrapers calls for an increasing demand for regular maintenance and cleaning of the large glass panes or windows of these buildings. Cleaning these windows, is not only tough and a risky job but also time consuming. Thus, an effort has been made to introduce a new system which not only reduces the human effort but also aims in cleaning the windows effectively as well as efficiently. This project aims to produce a clean view through the windows which helps in maintaining the aesthetic view of the building. This device can be used periodically for efficient cleaning of the external glass walls, as there is no involvement of a human being suspended from the top of the building. The Current device can be used as a replacement for an existing method in order to ensure safety of the workers.
\end{abstract}

Keywords: Glass panes, Windows, Cleaning, worker safety, Aesthetics.

\section{Introduction}

There are always a lot of glass windows in high rise buildings. All these panes of glass or windows need to be clean to be kept shining and nice to maintain its aesthetic view and for this job to be done the owners of the high rise buildings hire contractors to get the glass walls cleaned manually. This manual labor method is not only time consuming and dangerous for the person who cleans it, this also is considered to be costly affair. The problem statement can be summarized as below:

i. Safety of labor is preferred.

ii. Clean view via windows is preferable.

iii. Less time required in cleaning windows.

iv. Less or No labor involved and also effectively reduce the cost of labor. 
This system or machine being autonomous in its cleaning process also aims to ensure the time taken and the cost involved to carry out this process is greatly reduced when it is to be compared with the time taken and the labor cost involved when humans are hired for the cleaning of the external glass walls. This window cleaning system is designed to be compact and light weight so that companies can use it with great ease, without taking the struggle of having to hire men to clean their windows. Thus, this system can clean windows as long as it flat and plain.

\section{Literature Review}

In order to develop a new window cleaning system, a study was done on the various traditional methods which are used for window cleaning; as well as other robots which were developed to serve the same purpose.

Traditional methods are the ones where manual labor is used to clean the glass walls, there are different methods used to clean the glass walls ranging from people being suspended from the top of high rise buildings to a person using telescopic rods fitted with squeezes to clean windows of mid height buildings standing from the ground. Abseiling is one method which is used for cleaning of external glass walls where a person is hung in the air from the top of the building with his equipment strapped to his waist, Gondola is similar to abseiling but it's just that, in this method a huge platform is suspended from the top with ropes supporting the platform at it's either ends; and workers stand on this platform along with their necessary cleaning equipment, these two methods are mainly used for high rise buildings.

We also have other methods which are used for mid-height buildings and they are: Reach and Wash method worker uses a long telescopic rod fitted with the cleaning equipment and cleans the windows standing on the ground, Work Platform Method, the platform is mounted on locomotive such as a truck and its reach is much shorter when compared to Gondola, Scaffold or Ladder method is where a platform or ladder is fixed at one place and the worker climbs and stands on it to clean the windows.

\section{Proposed System}

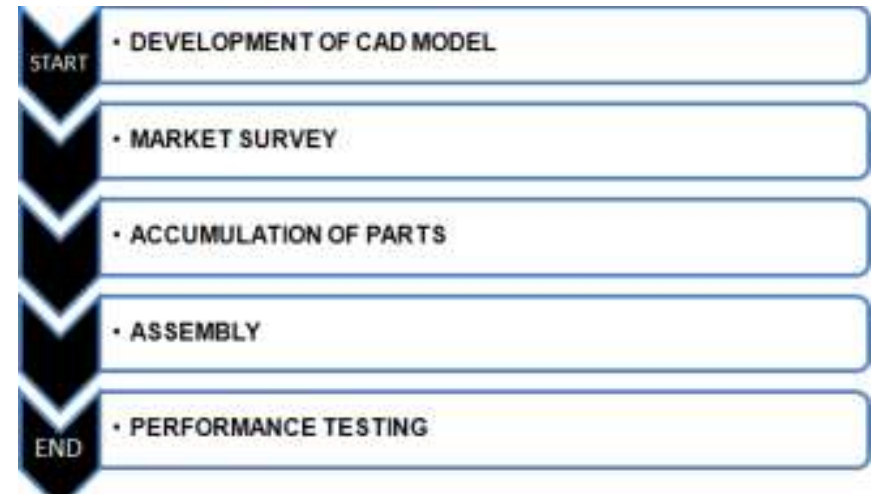

Figure 1: Flow chart of the proposed model preparation 


\subsection{CAD Model}
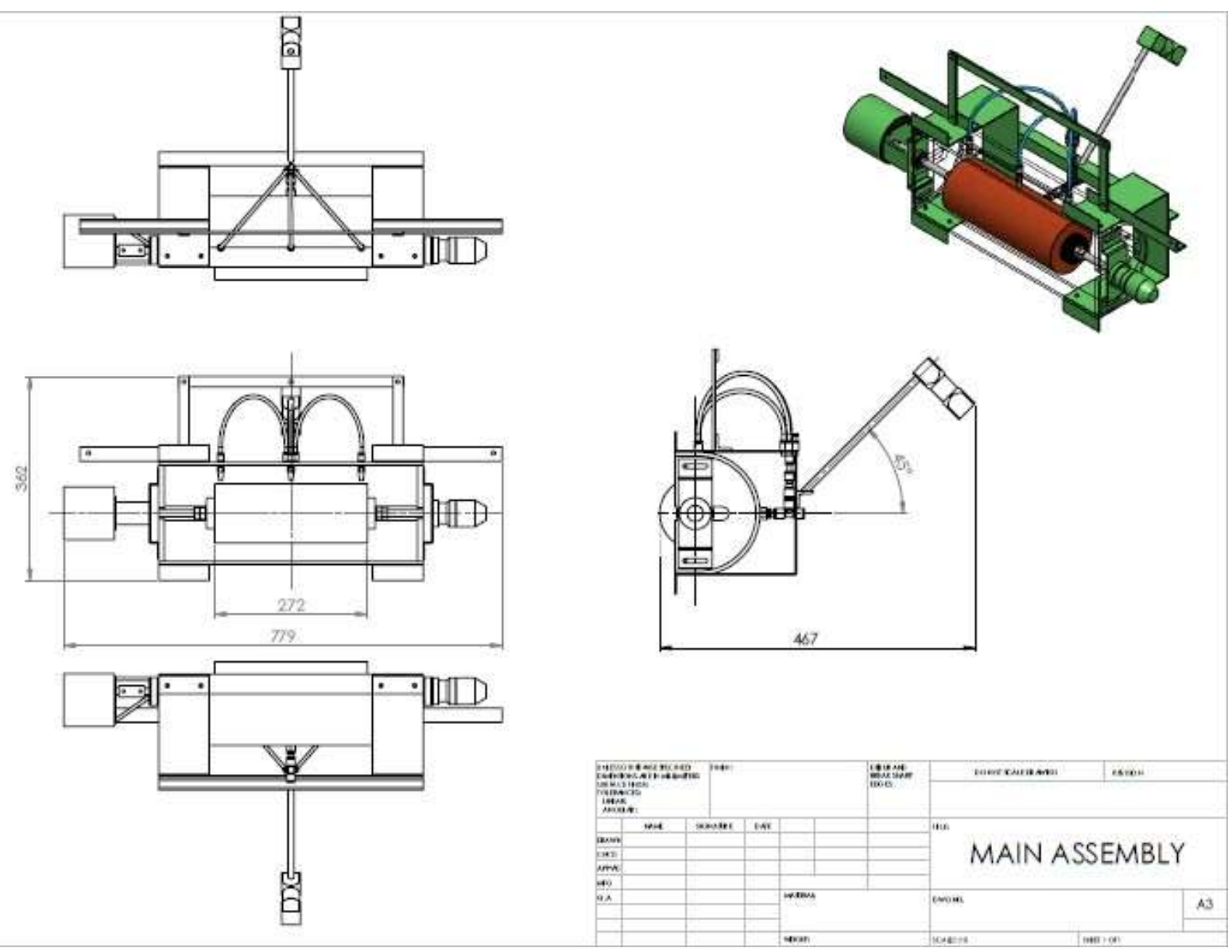

Figure 2: CAD drawings of the model

\subsection{Parts Description}

\begin{tabular}{|c|c|c|c|c|}
\hline $\begin{array}{l}\text { Sl } \\
\text { No }\end{array}$ & Part Name & $\begin{array}{c}\text { Number of } \\
\text { Units }\end{array}$ & Material & $\begin{array}{l}\text { Dimensions } \\
(\mathbf{m m})\end{array}$ \\
\hline 1 & Screw Rod & 1 & Stainless Steel & $\begin{array}{c}\mathrm{D}=12 ; \mathrm{L}=560 ; 1.75 \mathrm{p} \\
\mathrm{V} \text {-thread }\end{array}$ \\
\hline 2 & Brush & 1 & Nylon & $\mathrm{Di}=12 ; \mathrm{Do}=54 ; \mathrm{L}=330$ \\
\hline 3 & $\begin{array}{c}\text { Semi Cylindrical } \\
\text { Cover } \\
\bullet \quad \text { Sides } \\
\bullet \quad \text { Gap }\end{array}$ & 1 & Acrylic & $\begin{array}{c}\mathrm{L}=470 ; \mathrm{t}=6 ; \mathrm{R}=165 ; \\
\text { Curvature }=370 \\
\bullet \quad 170 \times 165 \times 10 \\
\bullet \quad 12 \times 70\end{array}$ \\
\hline 4 & Stiffener & 1 & Acrylic & $450 \times 25 \times 10$ \\
\hline 5 & Bearing 6201ZE & 2 & Steel & $\mathrm{Di}=1 ; \mathrm{Do}=32 ; \mathrm{t}=10$ \\
\hline 6 & Bearing Support & 2 & Acrylic & $50 \times 100 \times 16$ \\
\hline 7 & Bush & 1 & Steel & $\mathrm{D}=18 ; \mathrm{L}=45 ; \mathrm{Di}=12$ \\
\hline 8 & $\begin{array}{c}\text { Spray Nozzle } \\
\left(40^{\prime}\right)\end{array}$ & 1 & Brass & $\mathrm{Di}=4.9 ; \mathrm{Do}=2.9 ; \mathrm{L}=34$ \\
\hline 9 & $\begin{array}{c}\text { Spray Nozzle } \\
(15)\end{array}$ & 3 & Brass & $\mathrm{Di}=4.9 ; \mathrm{Do}=2.9 ; \mathrm{L}=34$ \\
\hline
\end{tabular}




\begin{tabular}{|c|c|c|c|c|}
\hline 10 & Motor & 1 & - & $\begin{array}{l}\text { 12V D.C. Variable Gear } \\
\text { Motor with Brush } \\
\text { rpm=500; O/P rpm }=55 \\
\mathrm{~T}=1500 \mathrm{Nm}\end{array}$ \\
\hline 11 & Transformer & 1 & - & $\begin{array}{c}230 \mathrm{~V} \mathrm{I} / \mathrm{P} 12 \mathrm{~V} \mathrm{O} / \mathrm{P} \\
\text { (step down) }\end{array}$ \\
\hline 12 & Speed Regulator & 1 & Plastic & 5 steps \\
\hline 13 & Clamping & 2 & Mild Steel & $\mathrm{t}=2$ \\
\hline 14 & Control Unit & 1 & Mild Steel & $\mathrm{L}=400 ; \mathrm{W}=250 ; \mathrm{t}=200$ \\
\hline 15 & Sump Tank & 1 & FRP & $24.5 \mathrm{Ltr}$ \\
\hline 16 & Pump & 1 & - & $\begin{array}{c}\text { Centrifugal Type } 0.5 \mathrm{hp} \\
(370 \mathrm{~W}) ; 6-28 \mathrm{~m} \text { Head } \\
\mathrm{Q}=3200-750 \mathrm{lph}\end{array}$ \\
\hline 17 & Pipe & 2 & Polyurethane & $\begin{array}{l}-8 \times 5.5 \\
-\quad 6 \times 4\end{array}$ \\
\hline 18 & Gear (Pulley) & 1 & Cast Iron & $\mathrm{D}=99 ; \mathrm{N}=31$ teeth \\
\hline
\end{tabular}

\subsection{Functions of parts employed}

\section{1) Rod:}

The rod is used to rotate the Brush about its central axis.

\section{2) Brush:}

The Brush is the Cleaning tool to perform the Cleaning operation of the vertical plain glass Walls.

\section{3) Semi Cvlindrical Cover:}

This part resists the flow path of the dust removed by the brush. it obstructs the Centrifugal action of the dust particles.

\section{4) Stiffener:}

This member is used to provide stiffness to the Cylindrical cover .

\section{5) Bearing 6201ZE:}

The bearing used is a double side closed type used to affix to members of a system.

\section{6) Bearing Support:}

This member is mainly used to support the Rod and displace and fix the brush at a desired height.

\section{7) Bush:}

The Bush is used to hold the rod and the motor extension together. 


\section{8) Sprav Nozzle:}

The nozzles are used to spray the water to the brush so as to wet them causing the cleaning of the window panes. Nozzles of angles 40 and $15^{\prime}$ are used for suitable coverage of brush surface area and optimum pressure.

\section{9) Motor:}

The Motor drives the brush and provides the desired speed of revolution for the brush to clean efficiently. A variable type is used to vary the speed of the brush for attributing to the thickness of the glass to be cleaned.

\section{0) Transformer:}

A step down type is used to reduce the amplitude of input and provide a stable input to the motor.

\section{1) Speed Regulator:}

This element is used to vary the speed of rotation of the brush.

\section{2) Clamping:}

The Clamping is used to provide a frame to the Cleaning Unit.

\section{3) Control Unit:}

The Control Unit Consists of Fuse, Mains Indicator, Rocker switch,Motor Control and Motor toggle switch. It is used to control the various parameters of different components.

\section{4) Sump Tank and Pump:}

Sump Tank is used to store the water required for cleaning and pump is used to regulate water of uniform pressure to the nozzles in the Cleaning Unit.

\subsection{Working of the device}

The installation of the Following unit and the Control unit at the roof top of the building to be cleaned. The Cleaning Unit is placed suspended along the face of the building. The connections are checked before starting the cleaning operation. The pump is placed at a head as per the range mentioned in the specifications of the pump. The working involves two stages of operation. They are

1. Downward motion.

2. Upward lift

\section{Downward motion}


The Mains of the Control unit is switched $\mathrm{ON}$ and the motor and the pump start running. The motor generates power to rotate the brush at a speed desired to clean the glass walls. This speed of rotation is regulated by a speed regulator in the Control unit. Once the water starts flowing to the nozzles, it wets the brush and the threaded screw fixed to the Cleaning unit is adjusted by adding suitable weights so as to create an optimum contact force between the brush and the glass wall. The rope wound to the pulley of the following unit is released gradually by the manually rotating the hand wheel to different positions marked previously and the Cleaning unit moves in the downward direction. This motion causes the rotating brush to make continuous contact and clean the dust present on the glass. The first set of nozzles continuously wet the brush and the other nozzle placed at the maximum radius of the cylindrical cover cleans the brush for further cleaning of the wall surface. The dust and water mixture projects out tangentially at the exiting side of the brush. This mixture flows outward due to centrifugal force and is restricted by the cylindrical cover. The dust now flows along the inner face of the cylindrical cover and exits through the drain provided at the bottom end of the cylindrical cover. The cleaning unit further moves to the bottom end of the vertical face of the building under cleaning. At the end of first stage of cleaning, the position of the key provided at the gear is reversed and the hand wheel is operated manually.

\section{Upward lift}

The cleaning unit is lifted slowly upwards by manually rotating the hand wheel. The rope suspended over the pulley now moves in the reverse direction and recoils. The brush further cleans the glass walls for the second time which ensures better cleaning and the dust and water mixture follows a reversed path as compared to the first stage. The mixture exits through the drain. When the Cleaning unit reaches the top most part of the building. The Follower unit is now moved to the next section of glass walls without lifting the Cleaning unit away from the wall is clamped so that it is fixed to its new position. The Cleaning unit is already engaged to the glass wall and the key is locked in position and the first stage is repeated. This process is done till the entire glass wall is cleaned. 


\section{Tests and results}

During the testing phase, the main concern was to calculate the amount of water that is being consumed to clean the particular chosen area of glass windows; what would be the duration to clean the whole area of glass windows as well as the time taken to clean each glass window and with how many swipes will it take to effectively clean the glass

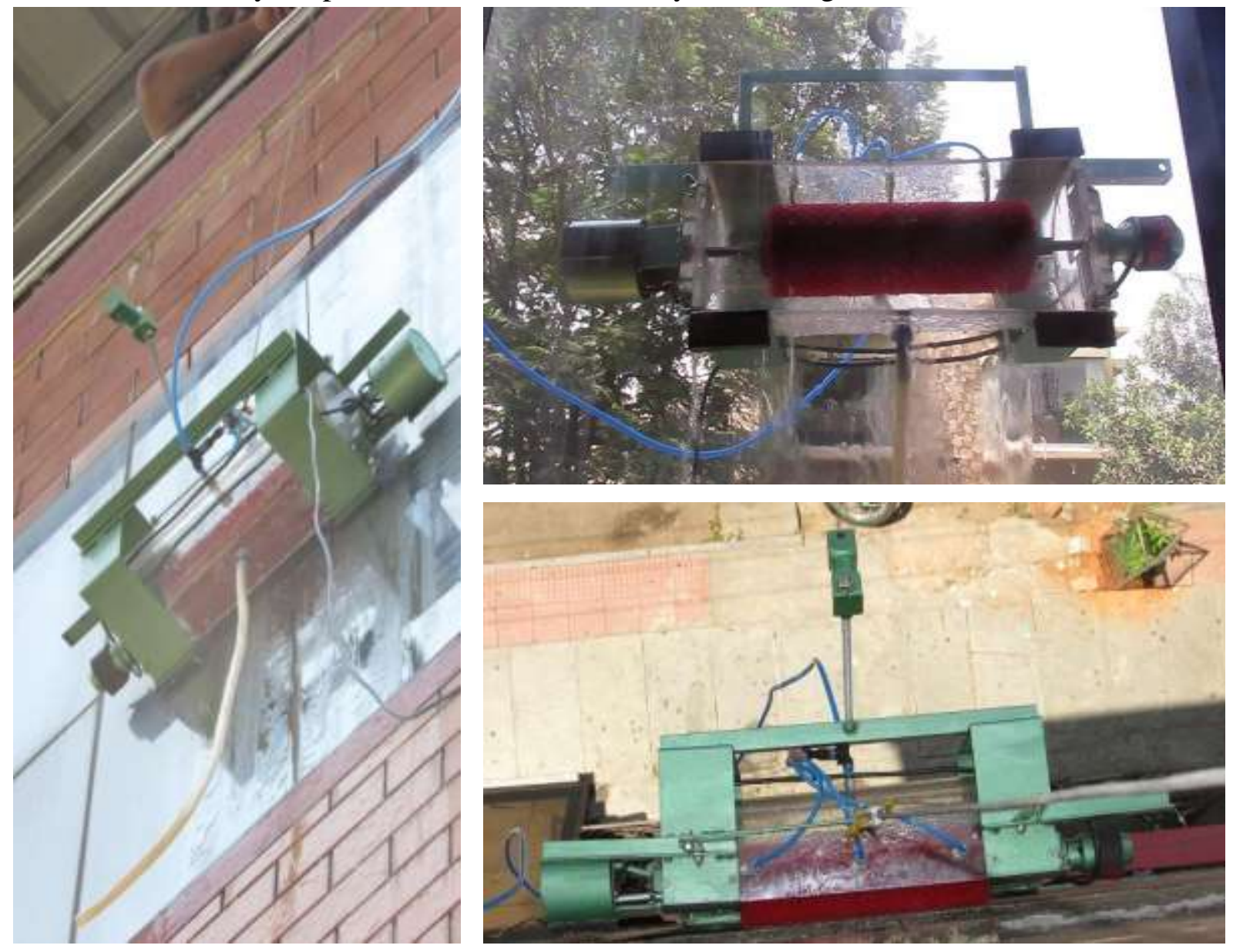

Figure 3: Actual Model in action

\subsection{Performance calculations}

After the device was put to test, the following were the data recorded for a set of 12 glass windows which were cleaned by this system.

\begin{tabular}{|l|l|}
\hline \multicolumn{1}{|c|}{ DESCRPITION } & \multicolumn{1}{c|}{ DATA (Bypass valve closed $)$} \\
\hline Single Glass Facade Dimension & $\mathrm{L}=900 \mathrm{~mm} \mathrm{~B}=900 \mathrm{~mm}$ Area $=8100 \mathrm{~mm}^{2}$ \\
\hline Time Taken to Clean Single Glass Facade & $\mathrm{T}_{1}=3.3 \mathrm{minutes}$ \\
\hline Water Flow-Rate & $\mathrm{Q}=5.568 \mathrm{pm}$ or $334.081 \mathrm{ph}$ \\
\hline Total Number of Glasses Cleaned & $\mathrm{N}=12$ \\
\hline Total Area Cleaned & Area $=12 * 8100=97200 \mathrm{~mm}^{2}$ or $9.72 \mathrm{~m}^{2}$ \\
\hline Total Volume of Water Consumed for 12 & $\mathrm{~V}_{\text {total }}=220.49$ litres \\
\hline Time Taken to Clean 12 Glass Facades & $\mathrm{T}_{12}=12 * 3.3=39.6$ minutes \\
\hline Total Non-Operating Time & $\mathrm{T}_{\mathrm{N} . \mathrm{O} .}=3 \mathrm{minutes}$ \\
\hline Total Time Taken & $\mathrm{T}=\mathrm{T}_{12}+\mathrm{T}_{\text {N.O. }}=39.6+3=42.6 \mathrm{minutes}$ \\
\hline
\end{tabular}




\section{Conclusion}

The system proves to be of use for commercial and residential building for the purpose of external glass cleaning. It can also be used for painting of multi-storeyed structure with a minor modification in the components used. The process of cleaning can also be automated by enabling the programs by using arduino boards or microcontrollers in future.

\section{References}

[1]. T. Yano, T. Suwa, M. Murakami and T. Yamamoto, "Development of a Semi SelfContained Wall Climbing Robot with Scanning Type Suction Cups", Proc. of the Intelligent Robot Systems Conference, pp. 900-905.

[2]. H.R. Choi, S.M. Ryew, T.H. Kang, J.H. Lee and H.M. Kim, "A wall climbing robot with closed link mechanism", Proc. of the Intelligent Robotic Systems Conference, vol. 3, pp. 2006-2011.

[3]. L. Shuliang, Z. Yanzheng, G. Xueshan, X. Dianguo and W. Yan, "A wall climbing robot with magnetic crawlers for sand-blasting. Spray-Painting and Measurement", High Technology Letters, vol. 10, pp. 86-88, 2000.

[4]. K. Autumn, Y. Liang, T. Hsieh, W Zesch, W.P. Chan, T. Kenny, R. Fearing and R.J. Full, "Adhesive force of a single gecko foot hair", Nature, vol. 405, pp. 681-5, 2000.

[5]. K. Autumn, M. Sitti, Y.A. Liang, A.M. Peattie, W.R. Hansen, S. Sponberg, T. Kenny, R. Fearing, J.N. Israelachvili and R.J. Full, "Evidence for van der Waals adhesion in gecko state", Proceedings of the National Academy of Sciences, vol. 99, pp. 12252-6.

[6]. Pneumatic Climbing Robots for Glass Wall Cleaning (Houxiang Zhang, Jianwei Zhang, Rong Liu and Guanghua Zong). Climbing and Walking Robots, Proceedings of the 7th International Conference CLAWAR 2004, Springer Berlin Heidelberg, DOI: 10.1007/3- 540-29461-9_104, pp. 1061- 1069.

[7]. Window Cleaning System With Water Circulation for Building Façade Maintenance Robot and its Efficiency Analysis (Sung Min Moon, Chang Yeob Shin, Jaemyung Huh, Kyeong Won Oh, and Daehie Hong). International Journal of Precision Engineering \& Manufacturing- Green Technology, Vol. 2, No. 1, pp. 65- 72, 10.1007/s40684-015-0009-8.

[8]. H. Zhang, G. Zong, "Pneumatic Robot for Glass-Wall Cleaning”, Chinese Hydraulics \& Pneumatics, No. 11, pp. 5-8, 2001.

[9]. W. Wang, G. Zong, "Controlling and Sensing Strategy for Window Cleaning Robot”, Hydraulics \& Pneumatics, No.1, pp. 4-7, 2001 